\title{
Strategies for Managing Shocking Global Crises in a Disruptive Environment: Proposal for a Intelligence Management Model
}

\author{
Manuel A. Fernández-Villacañas Marín ${ }^{\mathrm{a} 1}$ and Ignacio Fernández-Villacañas Marcos ${ }^{\mathrm{b} 2}$ \\ ${ }^{a}$ Technical University of Madrid, Spain. \\ ${ }^{\mathrm{b}}$ Cranfield University, UK.
}

\begin{abstract}
The high global vulnerability revealed by the current pandemic confirms the existence of a very threatening and disruptive environment. The development of new strategies is needed in response to the new shocking global disruptive crisis, analysing the use of new methodologies and digital tools for their early detection and prospective planning. This will allow the development of more proactive, effective, and efficient response plans, with minimal risks. The work considers the convenience of standardized use and optimisation of social welfare functions that integrate social, economic, and ecological variables and indicators, around the achievement of 17 Sustainable Development Goals of the UN 2030 Agenda, and 169 objectives associated with them.
\end{abstract}

Keywords. Shocking Crisis, Disruptive Environment, Strategic Anticipation, Prospective Planning, Social Welfare Functions, Sustainability.

\section{$1 \quad$ Introduction}

The current global pandemic has revealed a high international vulnerability to this type of threat and the inability of many nations to respond effectively to environmental uncertainty [1]. It seems clear that this pandemic will involve a profound change in lifestyles and a crisis in traditional economic systems, with a structural change that will lead us to a new global situation. This progressive increase in risk situations associated with infectious diseases could be the result of a rapid global change that is altering the relationship between humans and our environment [2]. In our opinion, the response from governments in many countries and from civil society has been delayed, improvised, ineffective and insufficient. But these threatening triggers are also present in other equally devastating phenomena: climate action failure, extreme weather, water crisis, natural disasters, human-made environmental disasters, cyberattacks, global governance failure, biodiversity loss, involuntary migration, social instability, etc. [3].

\footnotetext{
${ }^{1}$ Ph.D. Consultant in Logistics \& Management at M\&M Planning and Project Management, Associate professor at Technical University of Madrid, Spain; E-mail: manuel.fernandez@mm-ppm.com.

${ }^{2}$ Bachelor's degree in Aerospace Engineering, Master's degree in Big Data and Business Analytics, Candidate of Thermal Power Master's in science at Cranfield University, UK; E-mail: i.fernandez-villacanasmarcos@cranfield.ac.uk.
} 
In addition to reducing the vulnerability of the population through preventive actions and the management of sector-specific policies against each threat, it is necessary to develop multidisciplinary and multisectoral action systems for early detection and strategic anticipation, response planning in terms of resilient perspectives [4], both social, economic and environmental, as well as strategic crisis and post-crisis management, ensuring coordination between all the agencies involved, the necessary public-private collaboration and the necessary international cooperation [5].

Generalizing to other shocking global crises that may arise, it seems advisable to undertake in depth a restructuring of the methodology to manage them. To avoid surprises and improvisations, as well as deviant and insufficient responses, it is necessary to develop digital systems for strategic anticipation and prospective planning, in a real time strategy, facilitating early detection and the most effective and efficient response with minimal risk [6]. The objective of this work is to study the application of these new strategies based on the optimisation of the social welfare functions that are determined, and that integrate the most significant variables of the social, economic and ecological dimensions of the sustainable development goals of the UN 2030 Agenda.

The research has been developed under an exploratory and explanatory research methodology, to understand the problem posed, and the work has been structured in three sections. First, there is a Literature Review section on new strategic methodologies applicable in a disruptive environment. Second, the Methods section discusses the use of social welfare functions to support the impactful global crisis management strategy, building on the outline of the Sustainable Development Goals. Finally, the Results and Discussion section studies an optimisation model of social welfare functions to support global crisis management impacting, and proposes a model of a general action scheme that is considered to improve the models that are being used, contextualizing the importance of the new approach.

\section{Literature Review}

In recent years there have been very intense and rapid changes in a highly disruptive global environment, whose generating aspects act with total uncertainty and without adjusting to a previous historical pattern [7]. It is a new and important characteristic of today's world that very significantly conditions the definition of strategic plans. The possible shocking triggers already mentioned, capable of acting globally, are very much alive today. In this way, the environment in which the public sector, the private business sector and civil society operate is very different from usual, and presents new threats, risks and opportunities, against which it is necessary to react in advance [8].

Strategic anticipation is the ability to explore and monitor the future, allowing decision makers to protect their interests, seek and take advantage of opportunities, and ensure the achievement of their goals and objectives [9]. Deeply related to strategic anticipation is the concept of prospective, which is the systematic, multidisciplinary and participatory process to gather knowledge about the future and build medium and longterm visions, with the aim of informing the decisions that will be made in the present [10]. Among the purposes of prospective planning, it should be highlighted that of generating alternative visions of desired futures, that of providing impulses for action, that of promoting relevant information under a far-reaching approach, that of creating explicit alternative circumstances of possible futures, and to establish values and decision rules to achieve the best possible future [11]. 
On the other hand, strategic intelligence has evolved towards a polysemic concept [12] that is obtained from the analysis and integration of very varied information, which offers key conclusions about a problem, within its framework of relation with other existing problems. It consists of the use of methodologies and techniques that allow reducing the uncertainty that affects strategic decision making. The organizational utility of strategic intelligence derives from its ability to transform and assign information to those responsible for strategic decisions [9], facilitating the early detection of opportunities, threats and risks in the disruptive environment [13] and improving performance and success [14]. Many authors have criticized the strategic planning technique because they consider that it should be alternatively continuous instead of at certain intervals [15], and thus evolve towards a prospective planning that facilitates a more comprehensive perspective of the organization [16]. Achieving the ability to penetrate the future requires a change in the strategic attitude, abandoning the reactive attitude and developing a proactive, anticipatory, and preventive attitude.

To apply all these new strategies, it is necessary to have methodologies that allow knowing the economic and social impact of each project or initiative. The Cost-Benefit Analysis (CBA) [17] [18] estimates and adds the equivalent monetary value of the benefits and costs for the community of public, private, and public-private projects. To reach a conclusion about its suitability, all aspects of the project, positive and negative, must be expressed in terms of a common unit, which means that all financial and social benefits and costs must be measured in terms of their equivalent value, a through the estimation of "income and opportunity costs". The equivalent monetary value is based on information derived from consumer and producer market choices, analysing historical data and future estimates of the demand and supply of goods and services affected by the project, updated through a discount rate to be integrated.

Finally, according to the Bergson-Samuelson approach, a social welfare function [19] [20] is a qualitative mathematical construction that considers the welfare of a given set of individual preferences, assigning values of social utility to possible reasonable alternative states of feasible associations of its economic system and associating a social preference to each possible configuration of individual preferences. It represents the possible patterns of collective choice and the alternative social states of allocation, trying to achieve the optimal allocation of resources based on the preferences of the individuals of that society with respect to collective decisions.

\section{$3 \quad$ Methods}

Collective decision models, currently linked to interactive models of democracy [21], try to obtain criteria for the aggregation of individual preferences in social preferences. Analytically, the function of utility levels is obtained from the problem of maximising the social welfare function $W_{\text {Social }}$, which is qualitative, defined by the integration and interaction of individual utilities $U_{i}, i$ from 1 to the $n$ members of society:

Maximise $W_{\text {Social }}(U 1, U 2, \ldots U n)$ subject to restrictions

minimum individual utility, feasibility of allocations, and availability of resources.

In 2015 the UN established the Sustainable Development Goals (SDGs) within 2030 Agenda. Since then, sustainability has become an important aspect of management [22], which requires that the public and private sectors implicitly carry out the critical evaluation of their activities in economic, social and environmental terms [23], including responsibility and the ethics of social behaviour as well as the new requirements of 
citizens in the welfare economy. The SDGs, as a plan for global development, demand the interconnection of all social sectors as key development actors, and an unprecedented level of cooperation and collaboration between civil society, business, government, NGOs, foundations, and others for their achievement. Partnership and collaboration between the social sectors have become an essential paradigm of sustainable development [24], perhaps in response to the limitations of traditional methods of development led by States.

On the other hand, scenario planning is a tool that involves generating a series of scenarios described in depth, each of which talks about a possible different future for society, and considers how each different future could influence decision-making of global crisis management [25]. The focus of the strategy is on decision making and assumes that the future that will follow will be the result of decisions made in the present. It is therefore a sequential linear approach, but it assumes that in complex situations the future is unpredictable, changes rapidly, and that decision-making is strengthened by taking a more open and flexible approach to the future.

Integration into a strategic intelligence management joint model that uses maximised social utility functions and sustainable development goals, variables, and indicators, is considered an excellent basis for assuming prospective planning of response scenarios to potential shocking global crisis.

\section{$4 \quad$ Results and Discussions}

Before proposing such a model, it is necessary to assume a systemic conception of sustainability and sustainable development [26], and the deployment of the 17 SDGs and 169 objectives associated with them in measurable and integral composite indicators [27]. Then, the strategic intelligence management model would be based on the maximisation of the utility index functions that would use the quantitative (and not qualitative) variables of the deployment of the SDGs:

$$
\operatorname{Max}\left\{W_{S}\left(U_{1}, U_{2}, \ldots, U_{n}\right)\right\} \approx \operatorname{Max}\left\{U_{S}\right\}=\operatorname{Max}\left\{\sum_{i=1}^{n} U_{i}\right\}=\operatorname{Max}\left\{\sum_{j=1}^{169} p_{j} * f(S D G)_{j}\right\}
$$

where $W_{S}$ is a qualitative social welfare function, $U_{S}$ is its quantitative function,

and $f(S D G)$ is a function of the composite indications of the deployment of each objective.

This optimisation is subject to the following restrictions:

$$
\operatorname{Max}\left\{\sum_{j=1}^{169} p_{j} * f(S D G)_{j}\right\} \text { involves the resource allocation, which must be feasible }
$$

The joint strategic intelligence management model must permanently track the indicators that comprehensively explain the behaviour of possible triggers that generate vulnerability. As you can see in Fig. 1, the potential impact of the state and the evolution of the different crisis triggers and the potential impact on the established strategic objectives (SDG) must be analysed and determined ex ante, evaluating direct preferences and behaviour people (CBA). In all cases in which there is a possible shocking crisis, nuanced by the estimated level of probability of occurrence, the exhaustive generation of all possible prospective scenarios would proceed, with the help of big data, business 
analysis, artificial intelligence and simulation systems. Each scenario will involve the determination of a specific strategic response plan that will identify the public-private capacities that are necessary to guarantee an effective response, depending on the maximised function of social utility index, and generating the maximum difference between benefits and social costs, with minimal risk of error. So, action strategies and capacity building for strategic anticipation will depend on the dynamic balance between the comprehensive social benefits of the consequences of each possible shocking global crisis, and the comprehensive social cost of generating these capabilities. At the same time, direct action plans and the deployment of such capabilities must be developed, making it possible to turn the most desirable scenarios into those most likely to become reality. It is considered that the proposed model improves the models that are currently being used which do not guarantee the maximisation of social utility, considering as a line for future research its application to a real case, as well as its adjustment and validation.

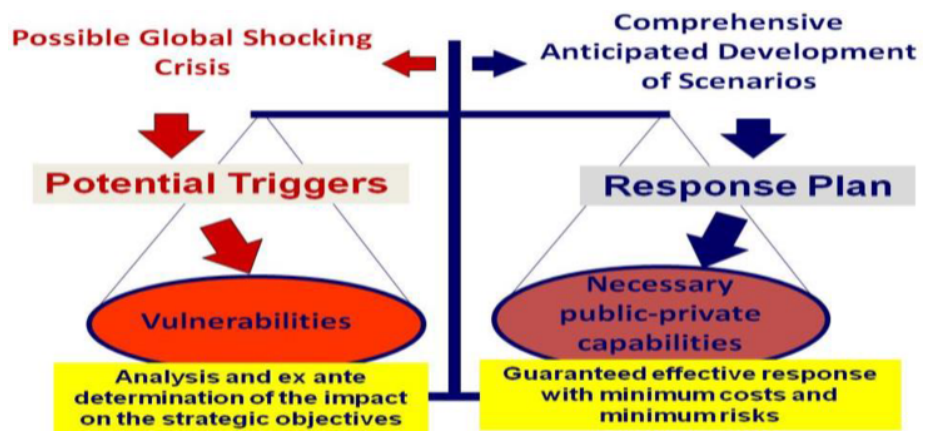

Fig. 1. Scenario planning: Generating alternative response plans [5]

\section{Conclusions}

The management of shocking global crises produced as a consequence of the current highly disruptive environment, requires new strategies of strategic anticipation, prospective planning and strategic intelligence that guide the application of digital technologies and can develop proactive, effective and efficient response plans, facing the currently used traditional management models which do not allow obtaining an adequate performance from digital technologies. International cooperation and public-private collaboration are essential and require a global standardization of actions, for which management models based on maximising social welfare functions on the SDGs and the use of CBA are useful.

\section{References}

1. Haarhaus, T. \& Liening, A.: Building dynamic capabilities to cope with environmental uncertainty: The role of strategic foresight. Technological Forecasting and Social Change, 155:120033, (DOI: 10.1016/j.techfore.2020.120033), (2020).

2. World Health Organization: Climate change and human health - risks and responses. Homepage https://www.who.int/globalchange/summary/en/index5.html, (2020).

3. World Economic Forum: The Global Risks Report 2020. Homepage http://www3.weforum.org/docs/WEF_Global_Risk_Report_2020.pdf, (2020). 
4. Rose, A.: Defining and Measuring Economic Resilience from a Societal, Environmental and Security Perspective. Springer Singapore, (DOI: 10.1007/978-981-10-1533-5), (2017).

5. Fernández-Villacañas, M.A.: Inteligencia estratégica logística frente a crisis globales emergentes. Anticipación estratégica y planificación prospectiva. VII Simposio Online de Logística y Competitividad, High Logistics Group, Medellín (Colombia) (2020).

6. Schuhly, A., Becker, F. \& Klein, F.: Real Time Strategy: When Strategic Foresight Meets Artificial Intelligence. Emerald Publishing (UK), (DOI: 10.1108/9781787568112), (2020).

7. Mufudza, T.: Dynamic Strategy in a Turbulent Business Environment, chapter In: Strategic Management. A Dynamic View. IntechOpen Homepage https:/www.intechopen.com/ online-first/dynamic-strategyin-a-turbulent-business-environment, (2018).

8. Fernández-Villacañas, M.A.: Strategic Intelligence and Decision Process: Integrated Approach in an Exponential Digital Environment. In: K. Sandhu (Ed) Leadership, Management, and Adoption Techniques for Digital Service Innovation. IGI-GLOBAL, Hershey (USA), (2020).

9. Balbi, E.R.: Anticipación estratégica el mayor desafío para la prevención y gestión de riesgos. At: http://www.academia.edu, (2015).

10. FOREN, A Practical Guide to Regional Foresight, Foresight for Regional Development Network, European Commission, Research Directorate General, Strata Programme, Brussels, At: http://foren.jrc.es, (2001).

11. Berger, G.: Phénoménologie du temps et prospective. Puf, París (France), (1964).

12. Palacios, J.M.: The Role of Strategic Intelligence in the Post-Everything Age, The International Journal of Intelligence, Security, and Public Affairs, Volume 20 - Issue 3 (DOI: 10.1080/23800992.2018.1532181), (2018).

13. Gilad, B.: Early Warning: Using Competitive Intelligence to Anticipate Market Shifts, Control Risk, and Create Powerful Strategies. Amacom, New York (USA), (2004).

14. Liebowitz, J.: Strategic Intelligence: Business intelligence, competitive intelligence, and knowledge management. Auerbach Publications, Boca Raton (USA), (2006).

15. Vecchiato R.: Strategic planning and organizational flexibility in turbulent environments. Foresight, 17(3), (2015).

16. Bratianu, C.: Strategic Thinking in Turbulent Times. In Bratianu, C., Dima, A.M. \& Hadad, S. (Eds.): Proceedings of the 11th IC on Business Excellence, Bucharest University of Economic Studies, (DOI: 10.1515/picbe-2017-0026), (2017).

17. Nas, T.F.: Cost-Benefit Analysis. Theory and Application (2nd Ed.), Lexington Books, Maryland (USA), (2016).

18. Boardman, A.E., Greenberg, D.H., Vining, A.R. \& Weimer, D.L.: Cost-Benefit Analysis. Concepts and Practice (5th Ed.), Cambridge University Press (DOI: 10.1017/9781108235594), (2018).

19. Kakwani, N. \& Son, H.H.: Social Welfare Functions and Development - Measurement and Policy Applications. Palgrave Macmillan (UK), (2016).

20. Sen, A.: Collective Choice and Social Welfare. An Expanded Edition. Harvard University Press, Cambridge, Massachusetts (USA), (2017).

21. Brill, M.: Interactive Democracy: New Challenges for Social Choice Theory. In: Laslier JF., Moulin H., Sanver M., Zwicker W. (eds) The Future of Economic Design. Studies in Economic Design. Springer, (2019).

22. Rosati, F. \& Diniz, L.G.: Addressing the Sustainable Development Goals in sustainability reports: The relationship with institutional factors. Journal of Cleaner Production Volume 215, 1 April, (2019).

23. Yun, G., Yalcin, M.G., Hales, D.N. \& Kwon, H.Y.: Interactions in sustainable supply chain management: A framework review. Int Journal of Logistics Management, Vol.30 No 1, (2019).

24. Stibbe, D.T., Reid, S. \& Gilbert, J.: Maximising the Impact of Partnerships for the SDGs. The Partnering Initiative, UN Department of Economic and Social Affairs, (2019).

25. Sayers, N.: Maximising the effectiveness of a scenario planning process. Perspectives, Vol 15:1, (DOI: 10.1080/13603108.2010.532014), (2011).

26. Gallopín, G.: Sostenibilidad y desarrollo sostenible: Un enfoque sistémico. División de Desarrollo Sostenible y Asentamientos Humanos, UN CEPAL, Chile (2003).

27. Lorenzo, C.: Medición de los Objetivos de Desarrollo Sostenible en la Unión Europea a través de indicadores compuestos. Documentos de Trabajo $\mathrm{n}^{\mathrm{o}}$ especial (2 época), Fundación Carolina, Madrid (2020). 